NASA/TM-2003-212295

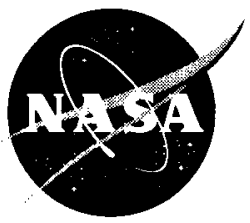

\title{
Control Study for Five-Axis Dynamic Spin Rig Using Magnetic Bearings
}

Benjamin Choi, Dexter Johnson, Andrew Provenza, and Carlos Morrison Glenn Research Center, Cleveland, Ohio

Gerald Montague

U.S. Army Research Laboratory, Glenn Research Center, Cleveland, Ohio

Prepared for the

Turbo Expo 2003

cosponsored by the American Society of Mechanical Engineers

and International Gas Turbine Institute

Atlanta, Georgia, June 16-19, 2003

National Aeronautics and

Space Administration

Glenn Research Center 


\section{Acknowledgments}

We would like to express a sincere appreciation to Ralph Jansen and Dr. Gerald Brown, NASA Glenn Research Center, for their significant technical contribution to the successful DSR demonstration.

This report is a formal draft or working paper, intended to solicit comments and ideas from a technical peer group.

This report contains preliminary findings, subject to revision as analysis proceeds.

This report is a preprint of a paper intended for presentation at a conference. Because of changes that may be made before formal publication, this preprint is made available with the understanding that it will not be cited or reproduced without the permission of the author.

The Propulsion and Power Program at NASA Glenn Research Center sponsored this work.

Available from

NASA Center for Aerospace Information 7121 Standard Drive

Hanover, MD 21076
National Technical Information Service 5285 Port Royal Road Springfield, VA 22100 


\title{
Control Study for Five-Axis Dynamic Spin Rig Using Magnetic Bearings
}

\author{
Benjamin Choi, Dexter Johnson, Andrew Provenza, and Carlos Morrison \\ National Aeronautics and Space Administration \\ Glenn Research Center \\ Cleveland, Ohio 44135 \\ E-mail: Benjamin.Choi@nasa.gov, Dexter.Johnson@nasa.gov, \\ Andrew.Provenza(a)nasa.gov, Carlos.Morrison@nasa.gov \\ Gerald Montague \\ U.S. Army Research Laboratory \\ Glenn Research Center \\ Cleveland, Ohio 44135 \\ E-mail: Gerald.Montague(a)nasa.gov
}

\begin{abstract}
The NASA Glenn Research Center (GRC) has developed a magnetic bearing system for the Dynamic Spin Rig (DSR) with a fully suspended shaft that is used to perform vibration tests of turbomachinery blades and components under spinning conditions in a vacuum. Two heteropolar radial magnetic bearings and a thrust magnetic bearing and the associated control system were integrated into the DSR to provide magnetic excitation as well as non-contact magnetic suspension of a $15.88 \mathrm{~kg}(35 \mathrm{lb})$ vertical rotor with blades to induce turbomachinery blade vibration.

For rotor levitation, a proportional-integral-derivative (PID) controller with a special feature for multidirectional radial excitation worked well to both support and shake the shaft with blades. However, more advanced controllers were developed and successfully tested to determine the optimal controller in terms of sensor and processing noise reduction, smaller rotor orbits, more blade vibration amplitude, and energy savings for the system. The test results of a variety of controllers that were demonstrated up to $10,000 \mathrm{rpm}$ are shown. Furthermore, rotor excitation operation and conceptual study of active blade vibration control are addressed.
\end{abstract}

\section{Introduction}

Today's turbomachinery components have extensive testing requirements and therefore there is a need to provide enhanced testing capabilities (Kosmatka ef al., 1992, 1993). Rotating components are expected to be used at very high rotational speeds. have extended life, and have better static and dynamic properties. The Dynamic Spin Rig (DSR) (see Figure 1) is used to perform research on turbomachinery blades and components under spinning conditions by rotating them in a vacuum chamber (Brown et al., 1984). During rotation the rotor is vibrated by using two voice-coil type linear electromagnetic shakers that apply axial forces to the rotor. Dynamics measurements are obtained yielding the blade's natural frequencies and damping.

Johnson ef al. (1997, 1998) replaced the bottom radial ball bearing of the DSR with a radial active magnetic bearing thereby providing magnetic suspension as well as magnetic excitation. It was proven that the magnetic bearing excited some blade modes to larger amplitudes and increased flexibility in excitation orientation (direction and phasing). This unique system that enables the magnetic bearing to act as a shaker provided an excitation force at critical blade modes to successfully complete various US engine company, NASA GRC (Duffy et al., 2000, 2002), and University of California turbine and/or fan blade damping tests.

Recently, the DSR was upgraded to have a fully suspended excitation system by replacing the remaining conventional radial ball bearings and the voice-coil type linear electromagnetic shakers. The new magnetic suspension and excitation system can provide longer run times at higher speeds and larger vibration amplitudes for rotating blades. Compared to the previous system, the new system can transmit more vibrational energy into the shaft and thus enable the excitation of higher blade modes observed in turbomachinery. Additionally, the magnetic bearing provides active control of stiffness and damping at the point of action. All of these features enable more useful testing to be performed.

For rotor levitation, a decentralized proportionalintegral-derivative (PID) controller and a centralized modal controller were developed first because they were easy to implement, and then a modern control technique with Kalman filtering was used to reduce sensor and processing noise. rotor orbits, and control current noise, which are critical to analyzing experimental damping test results.

\section{Test Facility Description}

The DSR provides experimental data for evaluation of vibration analysis methods for rotating systems. Bladed rotors up to $81 \mathrm{~cm}$ (32 in.) in diameter can be spun up to $20,000 \mathrm{rpm}$ by a speed regulated air motor. Before installation of the magnetic bearing, electromagnetic shakers were primarily used to apply oscillatory axial forces to the rotor shaft through a soft mounted rolling element thrust bearing. Strain gages, accelerometers, and optical blade-tip vibration sensors provide blade vibration signals. 


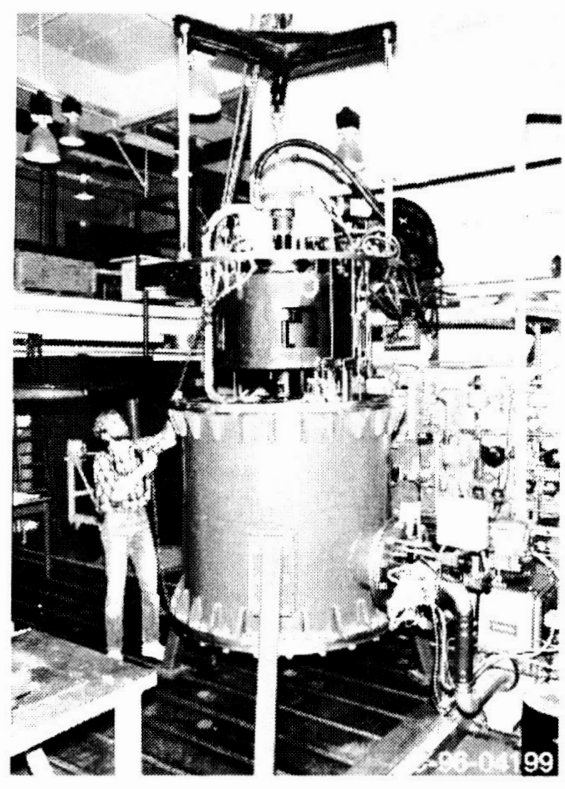

Figure 1: Dynamic Spin Rig Facility.

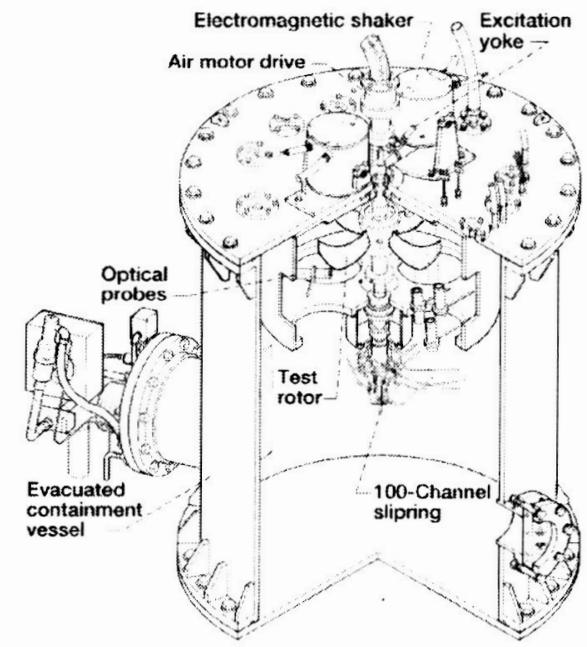

Figure 2: Cutaway drawing of Dynamic Spin Rig with all rolling element bearings.

Figure 2 is a cutaway drawing of the rig with two mechanical bearings supporting the rotor. Shown are the vacuum tank, the air motor drive, two electromagnetic shakers, a multi-blade rotor (with a vertical axis of rotation), a 100-channel slip ring assembly (which is located at the bottom of the rotor and is used to transmit signals from the rotor). The vacuum (down to 137.93 pascal $(0.02 \mathrm{psi})$ ) reduces the torque required to drive the disk and renders aerodynamic effects negligible.

A conventional dual disk type magnetic thrust bearing was mounted on the top to support the rotor. The radial magnetic bearing is a 4-pole heteropolar type. Each pole has 160 coil turns with an independent Pulse-Width-Modulated (PWM) amplifier. Its outer diameter of rotor lamination is $119.38 \mathrm{~mm}(4.7 \mathrm{in})$. It is operated using a maximum of $6 \mathrm{~A} /$ coil. The backup bearing radial gap distance is 0.254 $\mathrm{mm}(0.010 \mathrm{in})$ with a typical operating radial shaft excursion of about $0.127 \mathrm{~mm}(0.005 \mathrm{in})$ or less.

An analysis shows that the rig is able to run up to 20.000 rpm without exceeding the stress limit of the bearing laminations. Up to the date of this publication, running at more than $10,000 \mathrm{rpm}$ is not recommended until a complete health monitoring system for the rig is installed. Therefore, all of the experimental data in this paper have been shown up to $10,000 \mathrm{rpm}$.

\section{Control System}

The control system uses both classical and modern control techniques, which are implemented with the MS-DOS Turbo ANSI $\mathrm{C}$ programming language on a Pentium $\mathrm{I} / 200 \mathrm{MHz}$ PC. Two A/D input boards and two D/A output boards were used to get sensor signals and to send out the control command signals to the power amplifiers.

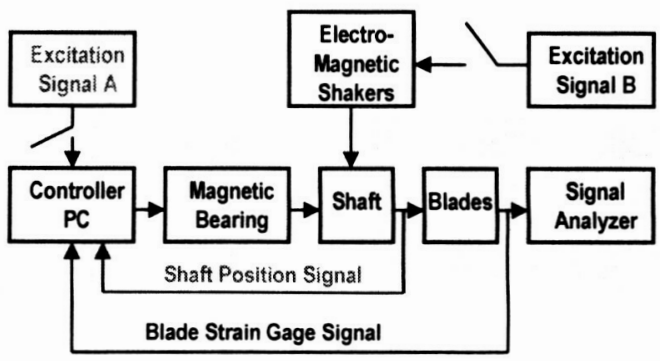

Figure 3: Control block diagram that includes all of the excitation, suspension, and blade vibration control elements that represent the system.

Figure 3 shows the control system block diagram that includes all of the suspension, excitation, and blade vibration control elements which represent the system. The controller has two primary components. One component provides the magnetic bearing suspension and the other provides the excitation (see Johnson et al., 1997, 1998, for the details). Also, a conceptual active blade vibration control can be achieved using feedback of blade strain gage signals within the magnetic bearing control loop. However, this paper focused on looking for an optimal controller for the magnetic suspension that can remove unnecessary high frequency signals for the damping test analysis.

A user-friendly controller cockpit window allows modification of the magnetic bearing parameters such as bias, stiffness, damping, and integral gain for the PID controller. It has a switch for a decentralized PID controller, centralized modal controller, control force integral feedback, and Kalman estimator. For each controller, a safe gain feature is triggered to protect the bearing system at higher speeds when the rotor orbit exceeds the predefined orbit size. Also, a whirling feature was implemented to investigate the dynamic behavior of the magnetically suspended rotor system as well as to check the backup bearings before the actual rotation. Whirling orbit size, starting angle, and the center point of the orbit are all user defined and aid in investigating the bounce mode and tilting mode. All of the above-mentioned features can be controlled separately for the lower- and upper bear- 
ings. In addition to an external comprehensive data collecting system, a simple data acquisition capability was added to the control cockpit window to monitor the system performance.

\section{Decentralized PD and PID Controller}

The first controller tested was a simple PD controller because it was easy to implement as

$$
i(x)=-\frac{\left(k+k_{s}\right) x+d \dot{x}}{k_{i}}
$$

where a proportional gain feedback $P=\left(k+k_{s}\right) / k_{i}$ and a differentiating feedback $D=d / k_{i}$. The proportional gain includes a term to offset the negative bearing stiffness $k_{s}$ and one to produce the actual bearing net stiffness $k$. The differentiating component controls the damping of oscillations. $D$ term was digitally realized as (current position-previous position)/sample time, which is about $52 \mu$ s. The control current was added to the bias current to obtain a linear relation between force and control current. At rigid body critical modes, even a simple decentralized PD controller was sufficient to suppress the vibration amplitude.

Next we tested an integral feedback scheme (see, for example, Schweitzer et al., 1994), which was easily implemented with the PD controller. In practice it is often desirable to keep a given rotor position independent of changes in the load. An additional integrating feedback-path in the controller compensated well for such change. Any deviation of the position $x$ is integrated over time slowly and added to the feedback until the error signal $e$ becomes zero.
In order to determine what combination of gains are useful and produce stable operation, a stability map was obtained experimentally by observing and recording what gain combinations produced instability. These gains show a stability surface under which stable operation of the system is achieved. The gain set in the middle range was selected and plugged into the controller as a safe gain set, which is triggered to protect the bearing system at higher speeds when the rotor orbit exceeds the predefined orbit size, while testing new controller parameters.

Figure 4 shows the rotor orbit and control current for each bearing in operation at $0 \mathrm{rpm}$ up to $10,000 \mathrm{rpm}$. The rotor orbits for the lower radial bearing were small and solid over the operating rage, but some high frequency noise level remained in the control current. However, the rotor orbits for the upper radial bearing coupled with the thrust bearing. which was somewhat shaky at the time of data collection, had relatively larger vibration amplitude and control current around critical modes. Notice that even large rotor orbits are within $\pm 0.254 \mathrm{~mm}$ ( \pm 10 mils) of displacement which is equivalent to $\pm 1 \mathrm{~V}$ in the figure.

\section{Centralized Modal Controller}

In order to have more vibration amplitude suppression and stable rotor orbits at critical modes, we tested a centralized modal controller that controls the two rigid body modes such as rigid body translation and rotation. Here, we assumed that the rotor is symmetric about the midpoint between the two radial bearings for the simplicity.

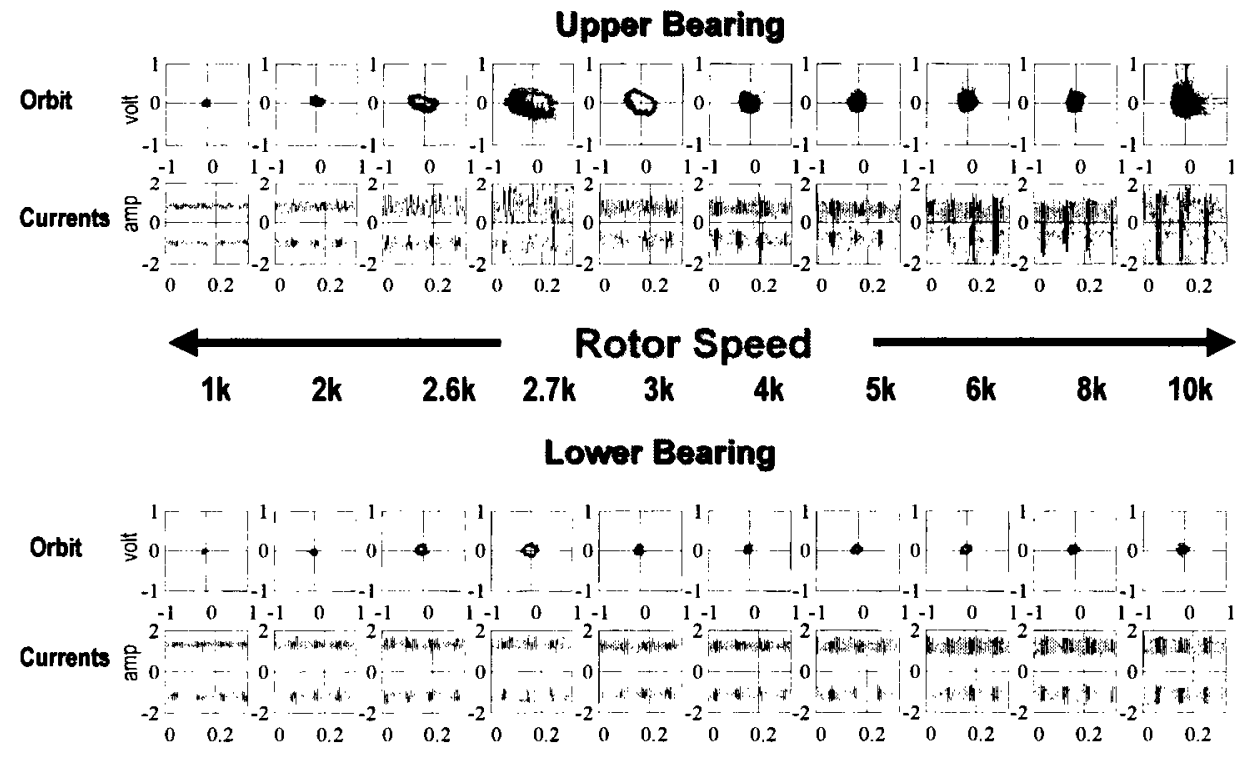

Figure 4: Rotor orbits and control current of the PID controller. 
Rigid Body Translation. The decentralized forces are

$$
\begin{aligned}
& F_{1}=-k_{1} x_{1}-c_{1} \dot{x}_{1} \\
& F_{2}=-k_{2} x_{2}-c_{2} \dot{x}_{2}
\end{aligned}
$$

where $F_{1}$ and $F_{2}$ are the $\mathrm{x}$-axis forces from the top and bottom radial bearings, respectively. The average horizontal translation of the rotor along the center of mass is $x_{a v}=\left(x_{1}+x_{2}\right) / 2$. Hence, the force on each side to compensate the horizontal deviation from the set point is

$$
F_{t r 1,2}=-\frac{1}{2}\left(\left(k_{1}+k_{2}\right) x_{a v}-\left(c_{1}+c_{2}\right) \dot{x}_{a v}\right)
$$

Rigid Body Rotation. The tilt angle of the rotor with respect to the vertical $y$-axis is $\theta=\left(x_{2}-x_{1}\right) / /$ where $l$ is the distance between the centers of the top and bottom radial bearings. The control torque to be created at the tilt angle $\theta$ is

$$
T=-k_{t i h t} \theta-c_{t i h t} \dot{\theta}
$$

where the rotational stiffness $k_{\text {tith }}=\left(k_{1}+k_{2}\right) \cdot l^{2} / 4$ and the rotational damping $c_{\text {tith }}=\left(c_{1}+c_{2}\right) \cdot l^{2} / 4$. The control forces to be exerted are $F_{r o l 1,2}=T / l$. Thus, combining $F_{\text {rot 1,2 }}$ with Equation (3) gives the centralized control force from each radial bearing:

$$
F_{\bmod 1,2}=-\frac{1}{4}\left(\begin{array}{l}
\left(k_{1}+k_{2}\right)\left(x_{1}+x_{2}\right)+\left(k_{1}+k_{2}\right) \cdot l \cdot \theta \\
+\left(c_{1}+c_{2}\right) \cdot l \cdot \dot{\theta}
\end{array}\right)
$$

The centralized $y$-axis forces can be obtained in the exact same way.
Figure 5 shows the overall rotor orbit and control current for each radial bearing with the modal controller in operation at $0 \mathrm{rpm}$ up to $10,000 \mathrm{rpm}$. The rotor orbits for upper- and lower bearings are getting better and more solid, but the control currents are equally distributed to the upper and lower bearings, resulting in amplifying the control current as well as high frequency sensor noise. However, the rotor vibration amplitudes at the first rigid body mode at about 2.700 $\mathrm{rpm}$ and another mode at about $10.000 \mathrm{rpm}$ were reduced by about $50 \%$. Since the decentralized PD controller worked well even at these modes, for this specific application, we couldn't see a big advantage using the modal controller which can be useful to reduce gyroscopic effects at higher speeds.

\section{Control Force Integral Feedback}

Next we tested a control force integral feedback, which is somewhat similar to the integral action of the PID control law described earlier. Simply adding an integral of the control force output to the output moves the shaft to the magnetic force center so that an average control force output can be minimized. Brown (Brown, 2001) successfully demonstrated this concept on a magnetic-bearing-supported energy storage flywheel at NASA GRC. It was proven that this technique maintained near zero average control current throughout the speed range without any operator attention.

When the control force integral was activated, the control force was integrated over time slowly and added to the feedback force output until the time-averaged control force becomes zero.

Figure 6 shows the overall rotor orbit and control current for each radial bearing with the force integral feedback in operation at $0 \mathrm{rpm}$ up to $10,000 \mathrm{rpm}$. When the control force integral feedback was activated, the magnetic force center, geometric backup bearing center, and zero sensor

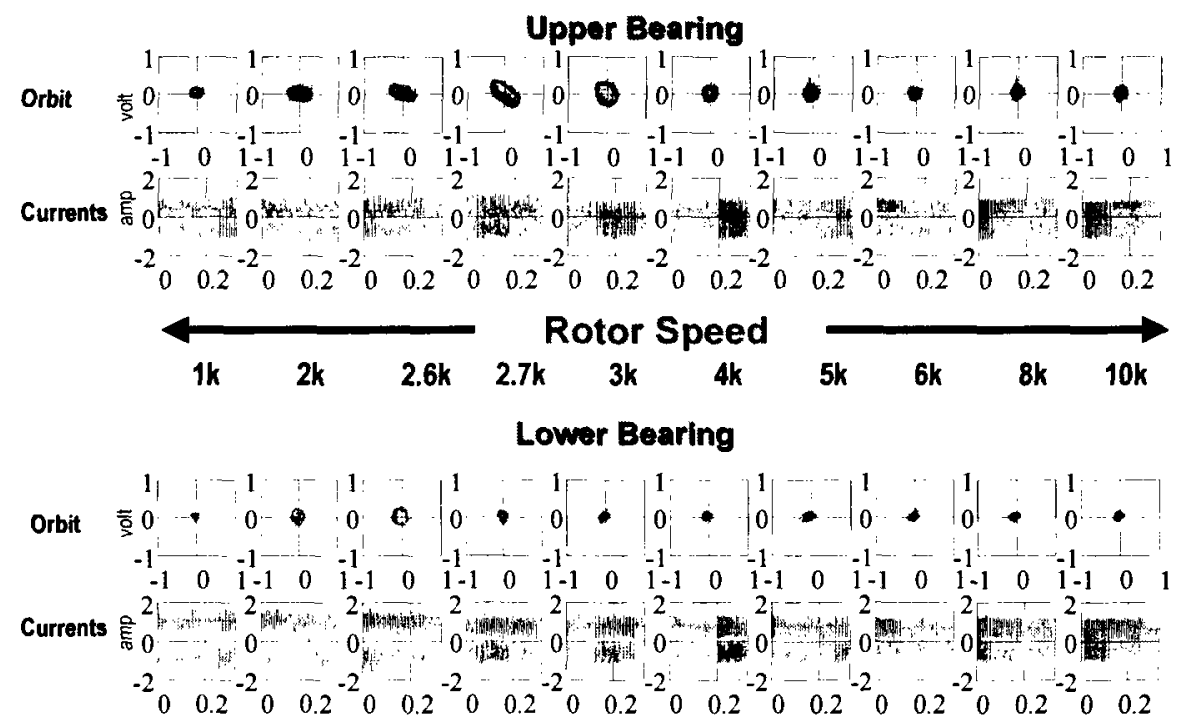

Figure 5: Rotor orbits and control currents of the modal controller. 


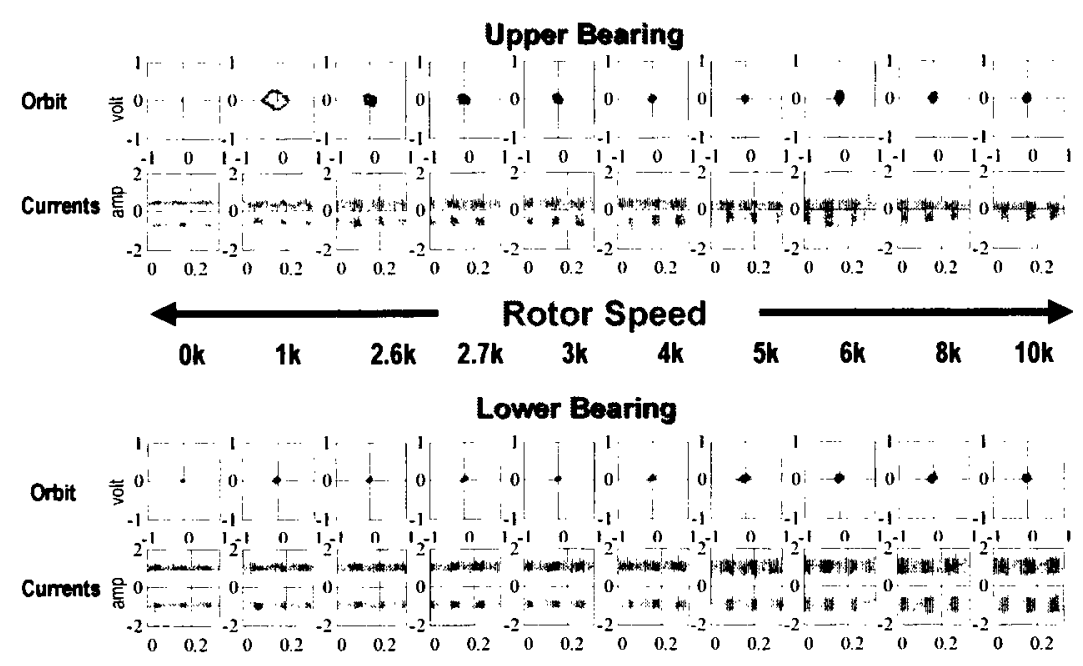

Figure 6: Rotor orbits and control currents of the PD controller with force integral feedback.

position were almost matched. In other words, the new DSR has almost perfect concentricity and alignment of the bearing system. Compared to the decentralized PID and centralized modal controllers, the rotor orbits and control currents for the upper- and lower bearings were significantly reduced. However, some high frequency noise level remained at the control current as well as rotor orbit.

Therefore, we continued to consider a modern control technique using Kalman filter that is inherently capable of reducing both measurement noise and processing noise.

\section{LQG (Linear-Quadratic-Gaussian) Regulator}

All of the above-mentioned controllers worked well in terms of the rotor orbit (position control) and control current level throughout the operating range up to $10,000 \mathrm{rpm}$. However, we wish to reduce high frequency magnetic bearing control noise, which may couple into the blade vibration measuring circuits, which is critical to good experimental damping test results.

To resolve this problem, a simple LQG regulator was developed based on a simple $2^{\text {nd }}$ order experimental plant model that approximates the rotor and magnetic bearing system. It was successfully demonstrated up to $10,000 \mathrm{rpm}$, significantly reducing the noise level and maintaining predefined gains throughout the speed range. This control law doesn't use a simple differentiation of the measured displacement signal, but a state estimation by a Kalman filter. Also it is quite useful in practice to trade off regulation performance with control effort for a given design specification. A simple design procedure is described as follows.

With the rotor levitated by the PD controller, a transfer function between the control force command signal and the shaft position signal was measured as shown in Figure 7. When we reduced the bandwidth of the analyzer to magnify the low frequency region, the magnitude and phase were near flat up to the first natural frequency. Therefore, by neglecting higher order dynamics beyond the first natural frequency, a simple $2^{\text {nd }}$ order open-loop plant model was approximated as

$$
t f(x / u)=\frac{k}{\left(a s^{2}-1\right)}
$$

where $k=1.19$ and the time constant $a=1 / w_{n}$. Based on this plant model with $w_{n}=45 \mathrm{~Hz}$ from Figure 7, a full state feed back matrix $F$ was computed first given our design specification, and the LQG-design was then followed in such a way as to minimize a cost function $J$ defined as the integral over weighted squares of state variables and control variables according to

$$
J(u)=\oint_{b}^{\infty}\left(x^{T} Q x+u^{T} R u+2 x^{T} N u\right) d t
$$

for a given state-space model with noise

$$
\begin{aligned}
& \dot{x}=A x+B u+G w \\
& y_{v}=C x+D u+H w+v
\end{aligned}
$$

where $w$ and $v$ are processing noise and measurement noise, respectively.

In our design specification, the respective weighting ratio for the square matrices $Q$ and $R$ is 1 to 10 for the upper bearing and 10 to 1 for the lower bearing to investigate experimentally how the different weighting ratio affects the system. We assumed no coupled effect between $x$ and $u$. thereby the third term in Equation (7) was neglected. We combined this with the optimal gain matrix $F$ to have a simple LQG regulator and then converted it into the discretetime model using a sample time $T_{s}=80 \mu \mathrm{s}$.

Figure 8 shows the overall rotor orbit and control current for each radial bearing with the LQG regulator in operation at $0 \mathrm{rpm}$ up to $10,000 \mathrm{rpm}$. It significantly reduced the high frequency noise as well as control current. It seems to show only bias current because noise level and control current were very low. Furthermore, as anticipated at the design stage by using the different weighting ratio (square matrices $Q$ and $R$ ) for the upper and lower bearings, the displacement 

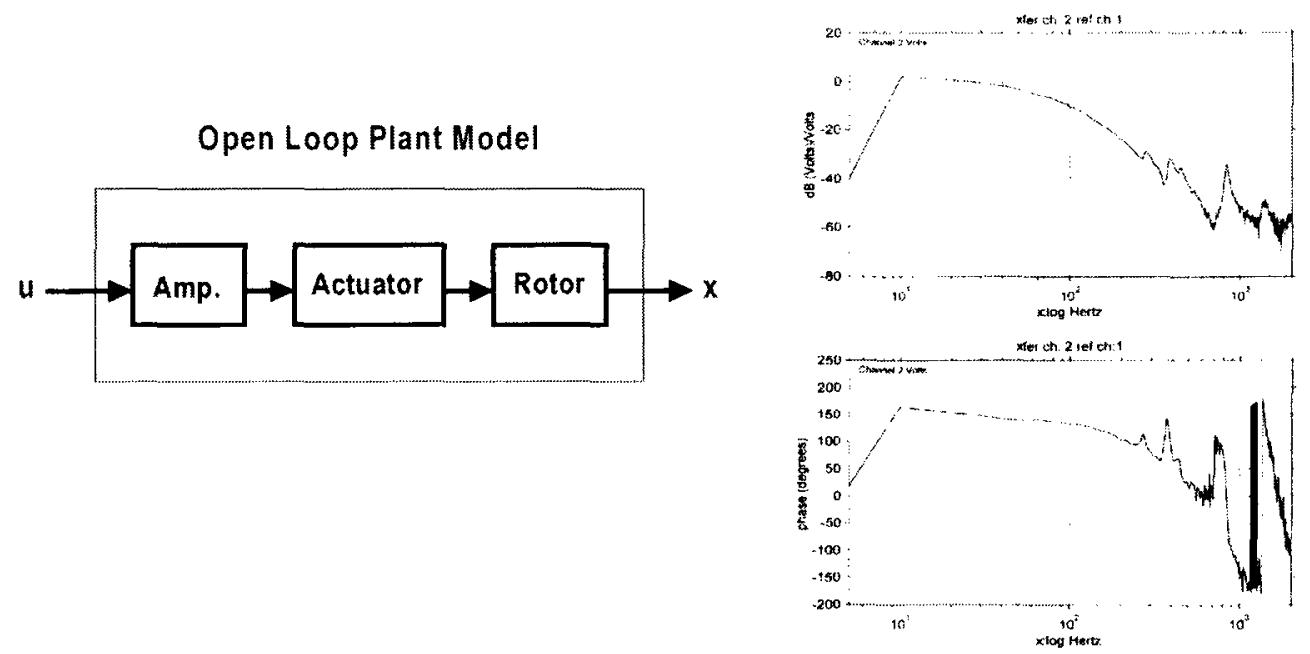

Figure 7: Experimental transfer function of open loop plant model at the upper radial magnetic bearing.
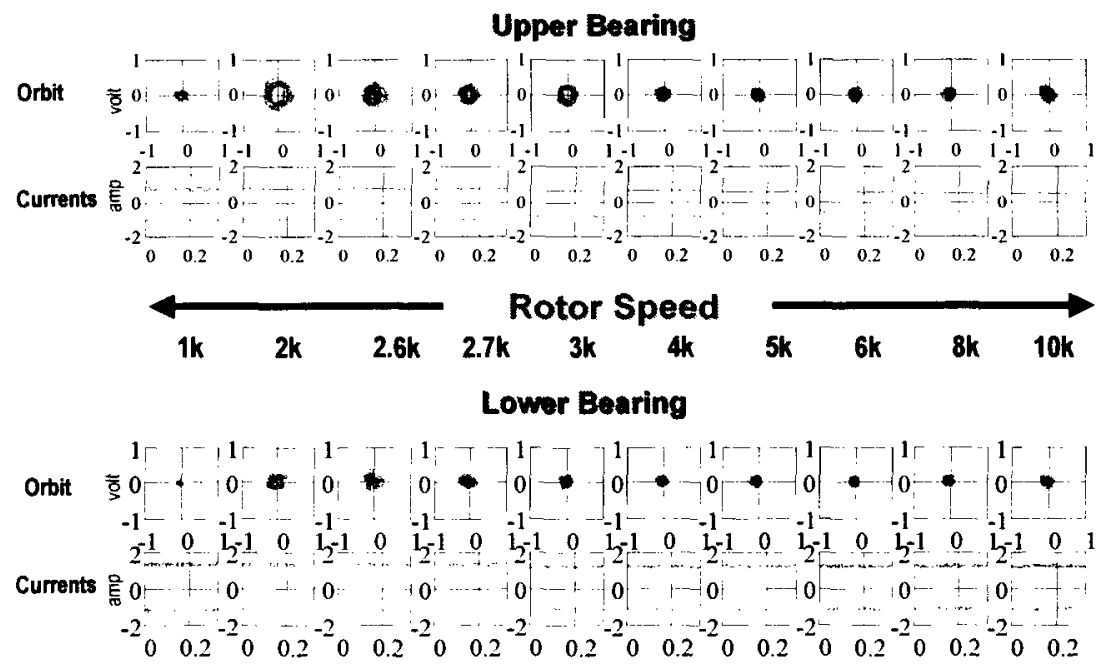

Figure 8: Rotor orbit and control current of the LQG regulator.
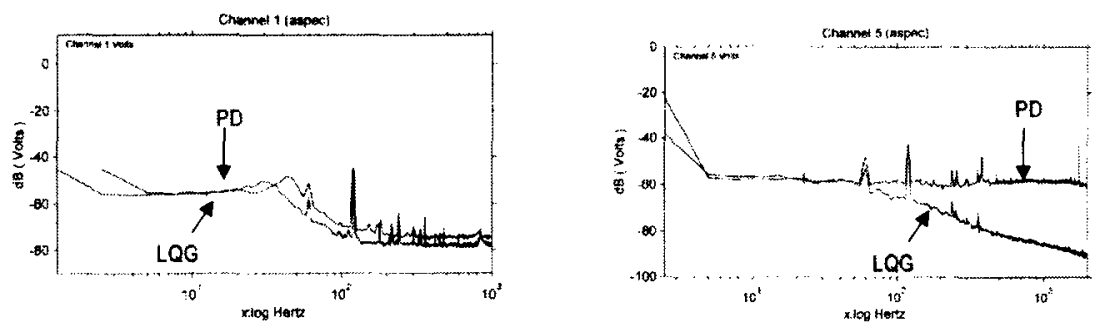

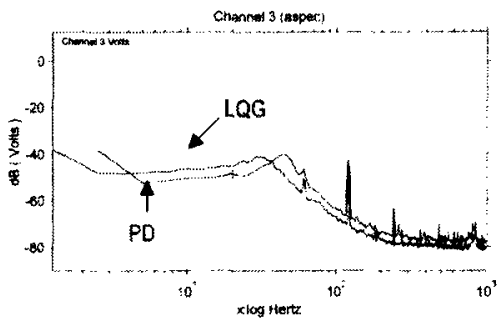

(a)

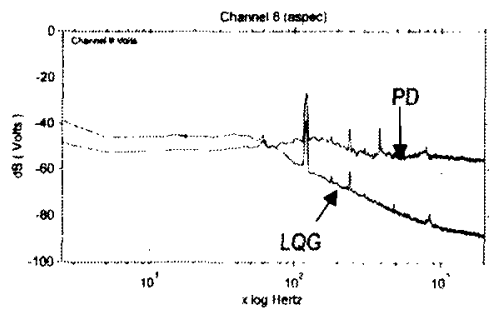

(b)

Figure 9: Power spectrum of (a) the upper- and lower rotor orbits and (b) control currents with the PD controller and LQG regulator, respectively. 
regulation (rotor orbit) for the lower bearing is better than that for the upper bearing, while the control effort for the upper bearing is better than that for the lower bearing.

Figure 9 shows the auto power spectrum of the rotor orbit and control current, respectively. As shown here, the PD control current contains a significant amount of high frequency noise. Compared to the PD controller, the LQG controller reduced the rotor displacement by about $50 \%$ above $35 \mathrm{~Hz}$, however it significantly reduced the high frequency control noise level. Also, much cleaner rotor orbits (more true for top then bottom) over the operating range were achieved as shown in Figures 4 and 8.

Figure 10 shows the controller transfer functions of PD and $L Q G$ regulator. It can be seen that the $L Q G$ regulator has similar $P$ (stiffness) and $D$ (damping) values as in the PD controller, but with a roll-off at about $150 \mathrm{~Hz}$. It is not surprising that the LQG controller ended up looking like a PD controller with a low pass filter since the rotor model used to synthesize the LQG controller was $2^{\text {nd }}$ order. The use of a higher order plant model may improve even further.

\section{Excitation Operation}

The rotor excitation is achieved by applying an excitation signal concurrently to the upper and lower radial bearings. At each bearing, excitation signals are applied simultaneously to the $\mathrm{x}$ - and $\mathrm{y}$-axes. This simultaneous excitation produces a resultant force vector with a magnitude and an angular orientation. The direction and amplitude of this force vector can be fixed in a non-rotating frame of reference relative to a test article, or made to rotate with the test article by enabling the "One-Per-Revolution" feature in the control code. A tiny mirror attached to the shaft reflects a beam of laser light once every rotation of the shaft. A sensor then converts the reflected light pulses to electrical pulses. The pulses are sent to an input channel on the $A / D$ board where they are used to trigger the "One-Per-Revolution" logic block, which then synchronizes the force vector with the rotating shaft.

In Figure 11, a schematic of the reference coordinates of the shaft at the upper radial bearing is shown. The $x-y$ axes are fixed and are representative of the stator frame of reference. The radius vector, $r$, is a representative vector of a fixed location on the moving shaft. This can be associated with the planar location of a set of blades with a hub on the shaft. The excitation force vector, $F_{e x}^{\prime}$, is the excitation force produced by the upper radial magnetic bearing which can be oriented in any radial direction. $\theta$ and $\phi^{t}$ are the vector angles for the radius vector and the excitation force vector at the upper radial magnetic bearing, respectively.
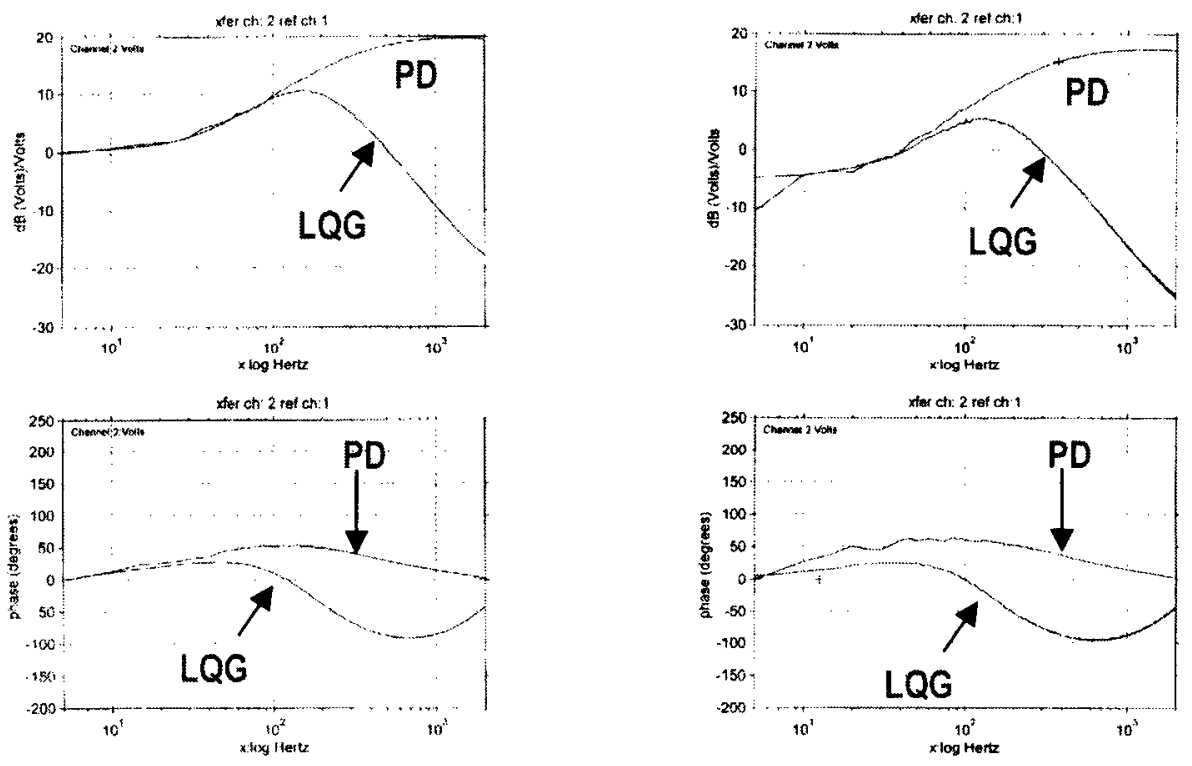

Lower radial bearing

Upper radial bearing

Figure 10: Bode plot of the PD controller and LQG regulator for the top and bottom radial bearings. 


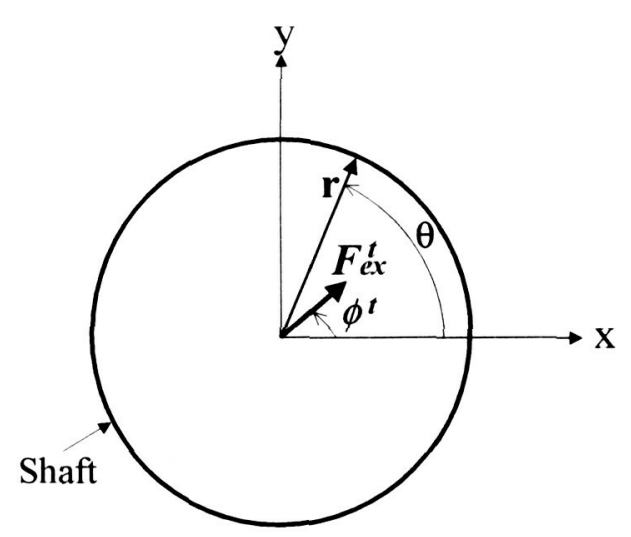

\section{Figure 11: Schematic of top down view of shaft at the upper radial bearing.}

The excitation signal can have a variety of forms. Firstly, it can be a sinusoidal signal of a single frequency, random,

broadband noise, or any general signal generated by a signal generator. Secondly, it can be generated in the feed forward form by the control code that is limited but quite similar to a signal generator function. Furthermore, a feedback blade vibration control law, which will be discussed in detail in the next section, can be added to the excitation signal. For most conditions the excitation has the following form:

$$
\begin{aligned}
& F_{e x}^{t}=F_{0}^{t} \sin \left(\psi^{t} t\right) \\
& F_{e x}^{b}=F_{0}^{b} \sin \left(\psi^{b} t\right)
\end{aligned}
$$

where $F_{0}^{t}$ and $F_{0}^{b}$ are the excitation signal amplitudes and $\psi^{\prime}$ and $\psi^{b}$ are the excitation frequencies at the upper and lower radial magnetic bearings, respectively. The force exerted on the $x-y$ axes at the upper radial bearing yields: where the sub-subscripts indicates the associated reference axis and the excitation angular frequency, $\eta^{t}=\dot{\phi}^{\prime}$. The forces exerted on the $x-y$ axes at the lower radial bearing, $F_{e x_{x}}^{b}$ and $F_{e x_{v}}^{b}$, can be derived in the similar way. The rotational speed of the shaft is given by $\omega=\dot{\theta}$.

$$
\begin{aligned}
& F_{e x_{x}}^{t}=F_{e x}^{t} \cos \left(\phi^{t}\right)=F_{0}^{t} \sin \left(\psi^{t} t\right) \cos \left(\phi^{t}\right)=F_{0}^{t} \sin \left(\psi^{t} t\right) \cos \left(\eta^{t} t\right) \\
& F_{e x_{y}}^{t}=F_{e x}^{t} \sin \left(\phi^{t}\right)=F_{0}^{t} \sin \left(\psi^{t} t\right) \sin \left(\phi^{t}\right)=F_{0}^{t} \sin \left(\psi^{t} t\right) \sin \left(\eta^{t} t\right)
\end{aligned}
$$

The magnetic bearing exciter has several modes of shaking the rotor to produce blade vibrations. The differences between the modes are due to the radial orientation, phasing, and frequency of the applied force. There are two primary modes of operation. One mode produces an excitation force with a fixed orientation with respect to the stator, i.e. $\phi$ is constant, which is called the stator-fixed mode. The other mode produces an excitation force with a fixed orientation with respect to the rotor, i.e., $\phi$ is not constant, which is called the rotor-fixed mode. For each mode of operation, the shaft may or may not be rotating. For non-rotating tests, where $\theta$ is constant, the stator fixed mode allows the force to be set at a desired orientation that may be optimal for large deflections. An example of this would be for a two-bladed test article in which the blades were positioned to lie coplanar to the plane made by the radial position vector, $r$, and the shaft vertical axis. For this blade position, the force would be best oriented perpendicular to the blade plane, where $\theta-\phi=\pi / 2$, and $\theta=$ const, to produce large amplitude "flapping" vibrations.

For rotating tests with the stator-fixed force, $\phi$ can be arbitrary since any setting produces the same vibratory response. The rotor-fixed mode produces an excitation force with a fixed orientation with respect to the rotor based upon a once-per-revolution signal. Operating this way for nonrotating tests, using an artificial once-per-revolution signal, allows whirling of the shaft to produce blade vibrations
( $\dot{\phi} \neq$ const and $\theta=$ const $)$. For rotating tests, the orientation of the excitation force follows the test article as it rotates ( $\theta-\phi=$ const and $\dot{\theta} \neq$ const $)$. Typically, one can use random noise to find the blade frequencies and then use a sinusoidal signal to drive at a particular frequency of interest.

In addition, since there are two radial bearings, rotor rigid body motions such as "bounce" and "tilt" can be excited at various frequencies.

Figure 12 shows the path of the shaft in the bounce or tilt mode and the position of the thrust bearing at its equilibrium position. In these displays, the "One-Per-Revolution" is deactivated and the shaft is being excited at a phase angle of $45^{\circ}$.

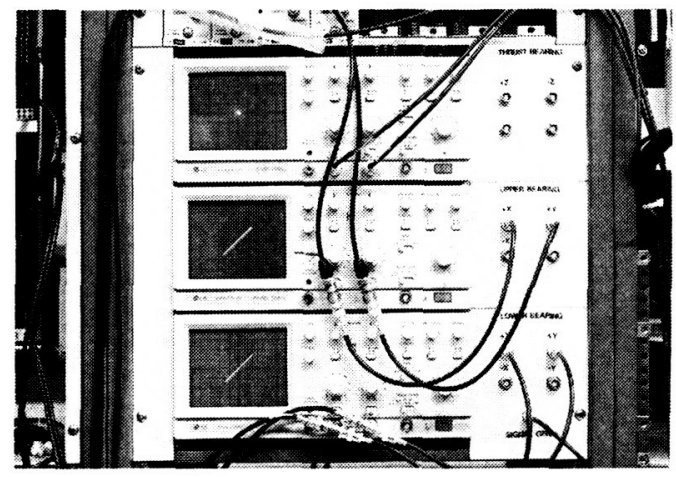

Figure 12: Position display screen for thrust, upper, and lower bearings. 


\section{Active Blade Vibration Control}

Gas turbine engines are currently being designed to have increased performance, lower weight and manufacturing costs, and higher reliability. Consequently, turbomachinery components, such as turbine and compressor blades, have designs that are susceptible to more serious vibration prob- lems and eventual in-service failure due to high cycle fatigue (HCF). To address this problem. some active blade vibration control concepts were developed and tested. Preliminary test results of using an active blade vibration control system, involving a rotor supported by the lower radial magnetic bearing in Figure 13 indicated promising results. These results were for a non-rotating two-bladed disk.

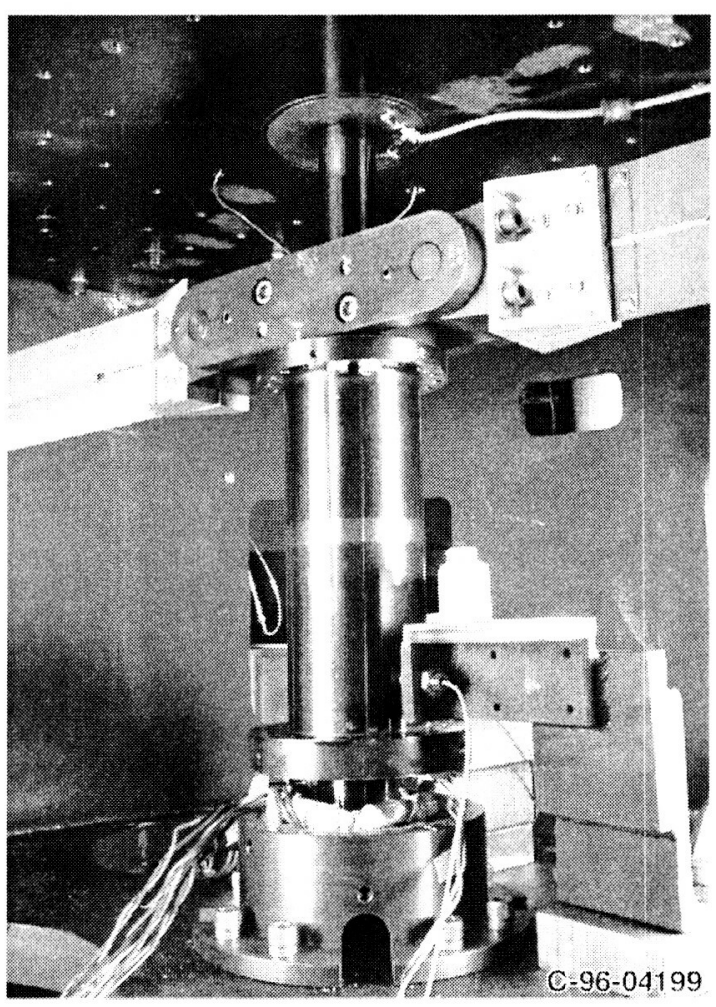

Figure 13: Lower magnetic bearing installed in DSR with viscoelastic damped composite plates.
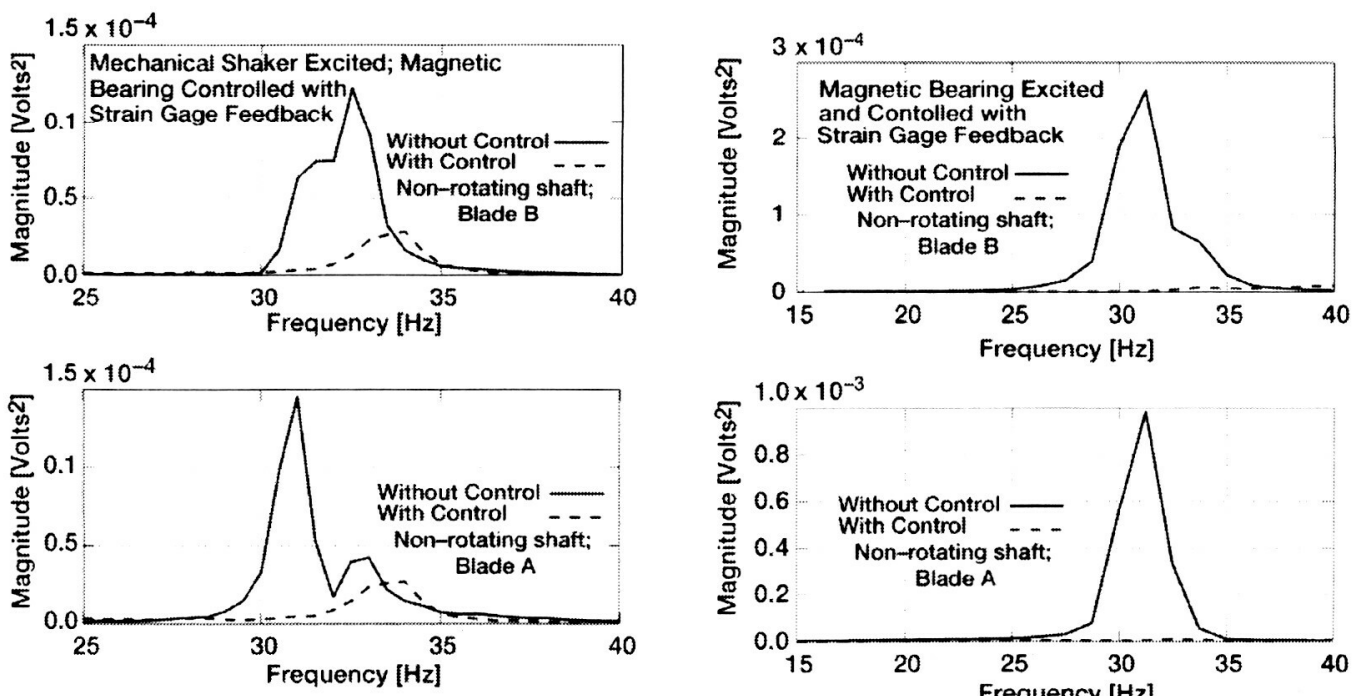

(a)

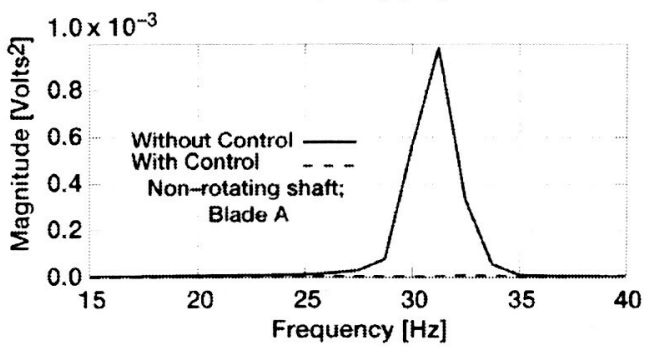

(b)

Figure 14: Power spectral density of flat plates with damping patches. 
The magnetic bearing control system for the active blade vibration control used a proportional-derivative (PD) control, which allows modification of magnetic bearing parameters such as stiffness and damping. By having this flexibility, gains can be programmed for various operating conditions. A transfer function between the excitation signal and the shaft position signal gives a spectral profile that indicates how well we can transmit energy to the system.

The blades are instrumented with strain gages and accelerometers. The strain gages are strategically located on the blades and the accelerometers are imbedded in the base support of the blades. Typically, transfer function data is obtained between the base accelerometer and the blade strain gage signals.

The electronic strain gage signal contains structural dynamic information about the blade vibration magnitude and phase. This electronic signal is then fed into the magnetic bearing controller and a proportional feedback gain is applied to it. The proportional feedback control gain that is used on the strain gage signal is added to the proportionalderivative control of the magnetic bearing position to produce the final output signal of the system. The gain can be adjusted to produce a faster response and limit steady state amplitude. This subsequently produces a force on the shaft which is opposing the motion of the blade which effectively reduces the blade vibration amplitude.

Active blade vibration control was achieved using feedback of blade strain gage signals within the magnetic bearing control loop (see Figure 3). Substantial reduction of vibration amplitude was achieved as shown in Figure 14. Also, vibration amplitude amplification was demonstrated and could be used to enhance structural mode identification, if desired.

Future active blade vibration control research will involve use of a five-axis fully magnetically suspended rotor with an upgraded $29.48 \mathrm{~kg}$ ( $65 \mathrm{lb})$ rotor, including rotating blades.

\section{Summary}

A fully suspended Dynamic Spin Rig (DSR) was developed to provide blade vibration excitation, and shaft suspension and control. The rig was upgraded by replacing conventional ball bearings and mechanical shakers with the 5-axis magnetic bearing system (two radial and one thrust bearings), thereby providing longer run times at higher speeds and larger vibration amplitudes for rotating blade tests. Various control techniques were investigated up to the maximum allowable speed of $10,000 \mathrm{rpm}$ to determine the optimal controller for the DSR. All the tested controllers worked well in terms of rotor orbit and control current level throughout the speed range. However, the LQG regulator showed the best performance in terms of noise reduction, control energy savings, and rotor orbit in relatively higher frequency region. Also rotor excitation strategy and a preliminary study on the blade vibration control were addressed. In the near future, the DSR with a new $29.48 \mathrm{~kg}$ (65 Ib) bladed rotor with $\mathrm{H}_{\infty}$ synthesis controller will be tested to improve the system robustness.

\section{References}

1. Brown. G.V., Kielb, R.E., Meyn, E.H., Morris, R.E., Posta, S.J., "Lewis Research Center Spin Rig and Its Use in Vibration Analysis of Rotating Systems." NASA TP-2304, May 1984.

2. Brown, G.V., "DC Control Effort Minimized for Magnetic Bearing Supported Shaft," NASA/TM-2001210605, 2001.

3. Choi, B., Johnson, D., Morrison, C., Mehmed. O.. "A Comparison Study of Magnetic Bearing Controllers for a Fully Suspended Dynamic Spin Rig," $8^{\text {th }}$ International Symposium on Magnetic Bearings, pp. 387-392, Mito, Japan, August 26-28, 2002.

4. Duffy, K., Bagley, R., Mehmed, O., "On a Self-Tuning Impact Vibration Damper for Rotating Turbomachinery," NASA/TM-2000-210215, August 2000, AIAA2000-3100-AIAA Joint Propulsion Conference, July 2000.

5. Duffy, K., Mehmend, O., "Self-Tuning Impact Dampers for Turbine Blades," 7th National Turbine Engine High Cycle Fatigue Conference, May 14-17, 2002.

6. Johnson, D., Mehmed, O., Brown, G.V., "Magnetic Excitation for Spin Vibration Testing," Physics and Process Modeling (PPM) and Other Propulsion R\&T, Cleveland, Ohio, May 1, 1997, NASA CP-10193, Volume II.

7. Johnson, D., Brown, G.V., Mehmed, O., "Magnetic Suspension and Excitation System for Spin Vibration Testing of Turbomachinery Blades," AIAA-98-1851.

8. Kosmatka, J.B., Lapid, A.J., and Mehmed, O., "Behavior of Spinning Laminated Composite Plates with Initial Twist-Experimental Investigation." Proceedings of the ASME Winter Meeting, November 1992.

9. Kosmatka, J.B., Lapid, A.J., "The Experimental Behavior of Spinning Pretwisted Laminated Composite Plates." Department of Applied Mechanics and Engineering Services, University of California, San Diego. Final Report on a Research Project Funded through NASA Research Grant Number NCC 3-173. Report No. SSRP-93/10.

10. Mehmed, O.. Kosmatka, J.B., "Damping Experiment of Spinning Composite Plates With Embedded Viscoelastic Material," Physics and Process Modeling (PPM) and Other Propulsion R\&T, Cleveland, Ohio, May 1, 1997, NASA CP-10193, Volume II.

11. Schweitzer, G., Bleuler, H., Traxler, A., Active Magnetic Bearings, vdf Hochschulverlag AG an der ETH Zurich, 1994. 


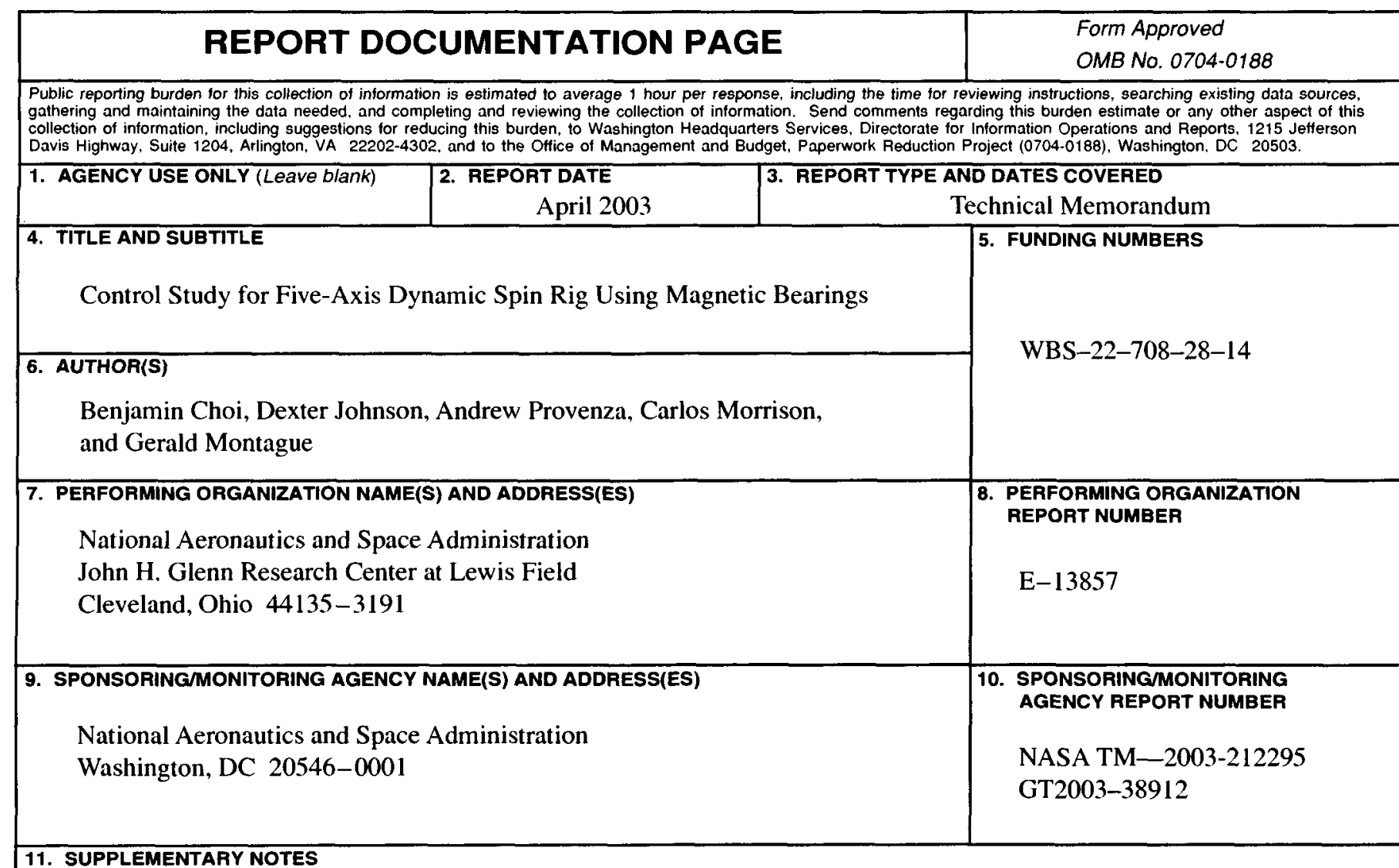

Prepared for the Turbo Expo 2003 cosponsored by the American Society of Mechanical Engineers and International Gas Turbine, Atlanta, Georgia, June 16-19, 2003. Benjamin Choi, Dexter Johnson, Andrew Provenza, and Carlos Morrison, NASA Glenn Research Center; Gerald Montague, U.S. Army Research Laboratory, NASA Glenn Research Center. Responsible person, Benjamin Choi, organization code 5930, 216-433-6040.

12a. DISTRIBUTION/AVAILABILITY STATEMENT 12b. DISTRIBUTION CODE

Unclassified - Unlimited

Subject Category: 07

Distribution: Nonstandard

Available electronically at http://gltrs.grc.nisa.gov

This publication is available from the NASA Center for AeroSpace Information, 301-621-0390.

13. ABSTRACT (Maximum 200 words)

The NASA Glenn Research Center (GRC) has developed a magnetic bearing system for the Dynamic Spin Rig (DSR) with a fully suspended shaft that is used to perform vibration tests of turbomachinery blades and components under spinning conditions in a vacuum. Two heteroplolar radial magnetic bearings and a thrust magnetic bearing and the associated control system were integrated into the DSR to provide magnetic excitation as well as non-contact magnetic suspension of a $15.88 \mathrm{~kg}$ (35 lb) vertical rotor with blades to induce turbomachinery blade vibration. For rotor levitation, a proportional-integral-derivative (PID) controller with a special feature for multidirectional radial excitation worked well to both support and shake the shaft with blades. However, more advanced controllers were developed and successfully tested to determine the optimal controller in terms of sensor and processing noise reduction, smaller rotor orbits, more blade vibration amplitude, and energy savings for the system. The test results of a variety of controllers that were demonstrated up to $10,000 \mathrm{rpm}$ are shown. Furthermore, rotor excitation operation and conceptual study of active blade vibration control are addressed.

\section{SUBJECT TERMS}

Magnetic suspension; Magnetic bearing; Rotor blades; Turbomachinery; Damping; Linear quadratic gaussian control; Classical control

\begin{tabular}{|c|c|}
\hline $\begin{array}{c}\text { 17. SECURITY CLASSIFICATION } \\
\text { OF REPORT } \\
\text { Unclassified }\end{array}$ & $\begin{array}{c}\text { 18. SECURITY CLASSIFICATION } \\
\text { OF THIS PAGE } \\
\text { Unclassified }\end{array}$ \\
\hline
\end{tabular}

19. SECURITY CLASSIFICATION OF ABSTRACT Unclassified 